\title{
EPQ Model for Trended Demand with Rework and Random Preventive Machine Time
}

\author{
Nita H. Shah, ${ }^{1}$ Dushyantkumar G. Patel, ${ }^{2}$ and Digeshkumar B. Shah ${ }^{3}$ \\ ${ }^{1}$ Department of Mathematics, Gujarat University, Ahmedabad, Gujarat 380009, India \\ ${ }^{2}$ Department of Mathematics, Government Polytechnic for Girls, Ahmedabad, Gujarat 380015, India \\ ${ }^{3}$ Department of Mathematics, L.D. College of Engineering, Ahmedabad, Gujarat 380015, India
}

Correspondence should be addressed to Nita H. Shah; nitahshah@gmail.com

Received 20 April 2013; Accepted 9 June 2013

Academic Editors: I. Ahmad, P. Ekel, and Y. Yu

Copyright (C) 2013 Nita H. Shah et al. This is an open access article distributed under the Creative Commons Attribution License, which permits unrestricted use, distribution, and reproduction in any medium, provided the original work is properly cited.

Economic production quantity (EPQ) inventory model for trended demand has been analyzed with rework facility and stochastic preventive machine time. Due to the complexity of the model, search method is proposed to determine the best optimal solution. A numerical example and sensitivity analysis are carried out to validate the proposed model. From the sensitivity analysis, it is observed that the rate of change of demand has significant impact on the optimal inventory cost. The model is very sensitive to the production and demand rate.

\section{Introduction}

An item that does not satisfy quality standards but can be attained after reprocess is termed as a recoverable item and the process is known as rework. It is observed that in an industrial sector, the rework reduced production cost and maintained quality standard of the item. Schrady [1] debated rework process. Khouja [2] formulated an economic lot-size and shipment policy by incorporating a fraction of defective items and direct rework. Koh et al. [3] and Dobos and Richter [4] discussed two production policies with options to order new products externally or recover old products. Chiu et al. [5] analyzed an imperfect rework process for EPQ model with repairable and scrapped items. Jamal et al. [6] advocated the policy for rework of defective items in the same cycle which was extended by Cárdenas-Barrón [7]. Widyadana and Wee [8] gave an analysis of these problems using an algebraic approach. Chiu [9] and Chiu et al. [10] discussed EPQ model by allowing shortages and considering service level constraint. Yoo et al. [11] discussed an EPQ model with imperfect production quality, imperfect inspection, and rework.

Meller and Kim [12], Sheu and Chen [13] and Tsou and Chen [14] studied Variants of EPQ model with preventive maintenance. Abboud et al. [15] analyzed an economic order quantity model by considering machine unavailability owing to preventive maintenance and shortage. Chung et al. [16] extended the previous model to compute an economic production quantity for deteriorating inventory model with stochastic machine unavailable time and shortage. Wee and Widyadana [17] revisited the previous model incorporating rework.

In this paper, we analyze an economic production quantity (EPQ) model with rework and random preventive maintenance time together when demand is increasing function of time. The consideration of random preventive maintenance time, rework, and trended demand in the model increases its applicability in the electronic and automobile industries. In this production system, produced items are inspected immediately. Defective items are stocked and reworked at the end of the production uptime. We will call these items as recoverable items. Out of these recoverable items, the fraction of the items will be labeled as "new" and rest will be scrapped. Preventive maintenance is performed at the end of the rework process, and the maintenance time is assumed to be random. When demand is increasing, shortages may occur which will be treated as lost sales in this study. It is observed that the rate of change of demand has significant impact on the optimal 
TABLE 1: Sensitivity analysis of $T_{1 a}$ and total cost when preventive maintenance time is uniformly and exponentially distributed.

\begin{tabular}{|c|c|c|c|c|c|}
\hline \multirow{2}{*}{ Parameter } & \multirow{2}{*}{ Percentage change } & \multicolumn{2}{|c|}{ Uniform distribution } & \multicolumn{2}{|c|}{ Exponential distribution $\lambda=20$} \\
\hline & & $T_{1 a}$ & TCT & $T_{1 a}$ & TCT \\
\hline \multirow{5}{*}{$A$} & $-40 \%$ & 0.1118836 & 2217.023407 & 0.165363168 & 3105.82179 \\
\hline & $-20 \%$ & 0.1127598 & 2396.444313 & 0.168010377 & 3225.883231 \\
\hline & 0 & 0.1136351 & 2574.499976 & 0.170676999 & 3344.12915 \\
\hline & $20 \%$ & 0.1145095 & 2751.208003 & 0.173362159 & 3460.599558 \\
\hline & $40 \%$ & 0.1153831 & 2926.585673 & 0.176064945 & 3575.33395 \\
\hline \multirow{5}{*}{$P$} & $-40 \%$ & 0.119 & 0.224 & 0.873011973 & 3769.650118 \\
\hline & $-20 \%$ & 0.116 & 0.220356527 & 0.280588937 & 3224.896639 \\
\hline & 0 & 0.1136351 & 2574.499976 & 0.170676999 & 3344.12915 \\
\hline & $20 \%$ & 0.0784111 & 2671.944386 & 0.123903512 & 3421.121046 \\
\hline & $40 \%$ & 0.0598742 & 2748.060997 & 0.09758743 & 3473.297234 \\
\hline \multirow{5}{*}{$P_{1}$} & $-40 \%$ & 0.1252239 & 2840.779326 & 0.179184671 & 3667.154126 \\
\hline & $-20 \%$ & 0.117738 & 2670.650277 & 0.17374104 & 3462.440106 \\
\hline & 0 & 0.1136351 & 2574.499976 & 0.170676999 & 3344.12915 \\
\hline & $20 \%$ & 0.1110459 & 2512.591082 & 0.168712009 & 3266.965218 \\
\hline & $40 \%$ & 0.1093473 & 2469.539689 & 0.167344624 & 3212.637461 \\
\hline \multirow{5}{*}{$a$} & $-40 \%$ & 0.0468611 & 2285.690117 & 0.081365729 & 2483.982152 \\
\hline & $-20 \%$ & 0.0736194 & 2419.311543 & 0.118822843 & 2928.274545 \\
\hline & 0 & 0.1136351 & 2574.499976 & 0.170676999 & 3344.12915 \\
\hline & $20 \%$ & 0.1801641 & 2784.239588 & 0.248801609 & 3743.389279 \\
\hline & $40 \%$ & 0.313401 & 3147.605249 & 0.385620567 & 4166.830717 \\
\hline \multirow{5}{*}{$b$} & $-40 \%$ & 0.1133496 & 2572.975288 & 0.170020919 & 3336.335153 \\
\hline & $-20 \%$ & 0.113492 & 2573.73768 & 0.170347969 & 3340.233353 \\
\hline & 0 & 0.1136351 & 2574.499976 & 0.170676999 & 3344.12915 \\
\hline & $20 \%$ & 0.1137789 & 2575.262185 & 0.171008033 & 3348.022553 \\
\hline & $40 \%$ & 0.1139235 & 2576.024314 & 0.1713411 & 3351.913594 \\
\hline \multirow{5}{*}{$x$} & $-40 \%$ & 0.1075459 & 2440.729188 & 0.165578265 & 3180.040146 \\
\hline & $-20 \%$ & 0.1105098 & 2506.778232 & 0.168074836 & 3261.520565 \\
\hline & 0 & 0.1136351 & 2574.499976 & 0.170676999 & 3344.12915 \\
\hline & $20 \%$ & 0.1169347 & 2644.037111 & 0.173391457 & 3427.954424 \\
\hline & $40 \%$ & 0.1204229 & 2715.549502 & 0.176225505 & 3513.094599 \\
\hline \multirow{5}{*}{$x_{1}$} & $-40 \%$ & 0.1131507 & 2451.633648 & 0.170247776 & 3220.242525 \\
\hline & $-20 \%$ & 0.1133924 & 2513.000758 & 0.170462207 & 3282.119979 \\
\hline & 0 & 0.1136351 & 2574.499976 & 0.170676999 & 3344.12915 \\
\hline & $20 \%$ & 0.1138787 & 2636.131758 & 0.17089215 & 3406.270464 \\
\hline & $40 \%$ & 0.1141232 & 2697.89656 & 0.171107662 & 3468.544359 \\
\hline \multirow{5}{*}{$h$} & $-40 \%$ & 0.1163864 & 2035.802579 & 0.196138784 & 2497.162768 \\
\hline & $-20 \%$ & 0.114993 & 2306.766649 & 0.18157314 & 2935.554059 \\
\hline & 0 & 0.1136351 & 2574.499976 & 0.170676999 & 3344.12915 \\
\hline & $20 \%$ & 0.1123112 & 2839.068303 & 0.162020977 & 3729.597492 \\
\hline & $40 \%$ & 0.11102 & 3100.535386 & 0.15486872 & 4096.262909 \\
\hline \multirow{5}{*}{$h_{1}$} & $-40 \%$ & 0.113733 & 2555.165605 & 0.171388527 & 3315.223296 \\
\hline & $-20 \%$ & 0.113684 & 2564.8349 & 0.171031253 & 3329.691775 \\
\hline & 0 & 0.1136351 & 2574.499976 & 0.170676999 & 3344.12915 \\
\hline & $20 \%$ & 0.1135862 & 2584.160837 & 0.170325715 & 3358.53567 \\
\hline & $40 \%$ & 0.1135373 & 2593.817484 & 0.169977356 & 3372.911591 \\
\hline
\end{tabular}


TABle 1: Continued.

\begin{tabular}{|c|c|c|c|c|c|}
\hline \multirow{2}{*}{ Parameter } & \multirow{2}{*}{ Percentage change } & \multicolumn{2}{|c|}{ Uniform distribution } & \multicolumn{2}{|c|}{ Exponential distribution $\lambda=20$} \\
\hline & & $T_{1 a}$ & TCT & $T_{1 a}$ & TCT \\
\hline \multirow{5}{*}{$S$} & $-40 \%$ & 0.1119752 & 2570.475444 & 0.15263831 & 3147.25954 \\
\hline & $-20 \%$ & 0.1129966 & 2572.958931 & 0.162618107 & 3255.743808 \\
\hline & 0 & 0.1136351 & 2574.499976 & 0.170676999 & 3344.12915 \\
\hline & $20 \%$ & 0.1140719 & 2575.549497 & 0.1774544 & 3418.940914 \\
\hline & $40 \%$ & 0.1143897 & 2576.310317 & 0.183312722 & 3483.929611 \\
\hline \multirow{5}{*}{$S_{c}$} & $-40 \%$ & 0.113643 & 2453.561123 & 0.170776446 & 3223.952673 \\
\hline & $-20 \%$ & 0.113639 & 2514.030563 & 0.170726744 & 3284.041215 \\
\hline & 0 & 0.1136351 & 2574.499976 & 0.170676999 & 3344.12915 \\
\hline & $20 \%$ & 0.1136311 & 2634.969362 & 0.17062721 & 3404.216467 \\
\hline & $40 \%$ & 0.1136271 & 2695.438718 & 0.170577378 & 3464.303169 \\
\hline
\end{tabular}

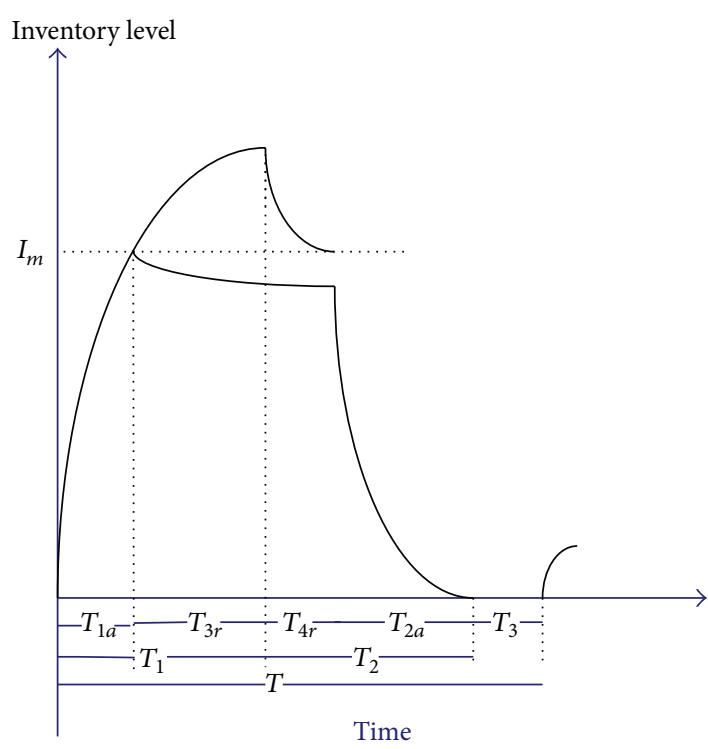

FIGURE 1: Inventory status of serviceable items with lost sales.

inventory cost. It is suggested that when demand is trended, preventive maintenance time should be controlled by recruiting well-qualified technicians. The uniform distribution and exponential distribution for preventive maintenance time are explored. The paper is organized as follows: Section 2 is about the mathematical development of the proposed problem. In Section 3, example and sensitivity are given. Conclusions are highlighted in Section 4.

\section{Mathematical Model}

Assumptions. (1) The inventory system under consideration deals with single item. (2) Standard quality items must be greater than the demand. (3) The production and rework rates are constant. (4) The demand rate, $R(t)=a(1+b t)$, is increasing function of time, where $a>0$ is scale demand and $0<b<1$ denotes the rate of change of demand. (5) Setup cost for rework process is zero or negligible. (6) Recoverable items are spawned during the production uptime, and scrapped items are produced during the rework uptime.
The status of the serviceable inventory is depicted in Figure 1. Production occurs during $\left[0, T_{1 a}\right]$. In phase $x$ defective items per unit time are to be reworked. The rework process starts at the end of the predetermined production uptime. The rework time ends at $T_{3 r}$ time period. The different production processes of the material and defective items result in different product rates. During the rework, some rejected and scrapped items will occur. LIFO policy is assumed for the production system. So, serviceable items during the rework uptime are utilized before the fresh items from the production in uptime. The new production run is started when the inventory level reaches zero at the end of $T_{2 a}$ time period. It may happen that the production may not start at $T_{2 a}$ time period because unavailability of the machine is randomly distributed with a probability density function $f(t)$. The nonavailability of machine may result in shortage during $T_{3}$ time period. The production will resume after the $T_{3}$ time period.

From the above description, the inventory level in a production uptime period is governed by the differential equation

$$
\frac{d I_{1 a}\left(t_{1 a}\right)}{d t_{1 a}}=P-R\left(t_{1 a}\right)-x, \quad 0 \leq t_{1 a} \leq T_{1 a} .
$$

The inventory level in a rework uptime is

$$
\frac{d I_{3 r}\left(t_{3 r}\right)}{d t_{3 r}}=P_{1}-R\left(t_{3 r}\right)-x_{1}, \quad 0 \leq t_{3 r} \leq T_{3 r} .
$$

The inventory level in a production downtime is

$$
\frac{d I_{2 a}\left(t_{2 a}\right)}{d t_{2 a}}=-R\left(t_{1 a}\right), \quad 0 \leq t_{2 a} \leq T_{2 a} .
$$

The inventory level in a rework downtime is

$$
\frac{d I_{4 r}\left(t_{4 r}\right)}{d t_{4 r}}=-R\left(t_{4 r}\right), \quad 0 \leq t_{4 r} \leq T_{4 r}
$$


Under the assumption of LIFO production system, the inventory level of good items depletes at a constant rate during rework uptime and downtime. The inventory level is governed by

$$
\frac{d I_{3 a}\left(t_{3 a}\right)}{d t_{3 a}}=0, \quad 0 \leq t_{3 a} \leq T_{3 r}+T_{4 r} .
$$

Using $I_{1 a}(0)=0$, the solution of (1) is

$$
I_{1 a}\left(t_{1 a}\right)=(P-a-x) t_{1 a}-\frac{a b}{2} t_{1 a}^{2}, \quad 0 \leq t_{1 a} \leq T_{1 a}
$$

which is the inventory level during $\left[0, T_{1 a}\right]$. Hence, the total inventory in a production uptime is

$$
\begin{aligned}
T I_{1 a} & =\int_{0}^{T_{1 a}} I_{1 a}\left(t_{1 a}\right) d t_{1 a} \\
& =(P-a-x) \frac{T_{1 a}^{2}}{2}-\frac{a b}{6} T_{1 a}^{3} .
\end{aligned}
$$

Using $I_{3 r}(0)=0, I_{4 r}(0)=0$, the total inventory of serviceable items for the rework uptime and rework downtime is

$$
\begin{gathered}
T I_{3 r}=\left(P_{1}-a-x_{1}\right) \frac{T_{3 r}^{2}}{2}-\frac{a b}{6} T_{3 r}^{3}, \\
T I_{4 r}=a\left[\frac{T_{4 r}^{2}}{2}+\frac{b}{3} T_{4 r}^{3}\right],
\end{gathered}
$$

respectively.

Using $I_{2 a}\left(I_{2 a}\right)=0$, the total inventory level of a production downtime is

$$
T I_{2 a}=a\left[\frac{T_{2 a}^{2}}{2}+\frac{b}{3} T_{2 a}^{3}\right] .
$$

The maximum inventory is

$$
I_{m}=I_{1 a}\left(T_{1 a}\right)=(P-a-x) T_{1 a}-\frac{a b}{2} T_{1 a}^{2}
$$

and hence, the total inventory in a rework uptime is

$$
T I_{3 a}=I_{m}\left(T_{3 r}+T_{4 r}\right) .
$$

Now, let us analyze the inventory level of recoverable items (Figure 2).

The inventory level of recoverable items in a production uptime is governed by the differential equation

$$
\frac{d I_{r 1}\left(t_{r 1}\right)}{d t_{r 1}}=x, \quad 0 \leq t_{r 1} \leq T_{1 a} .
$$

Since initially there are no recoverable items, that is, $I_{r 1}(0)=$ 0 , the solution of (12) is

$$
I_{r 1}\left(t_{r 1}\right)=x t_{r 1}, \quad 0 \leq t_{r 1} \leq T_{1 a} .
$$

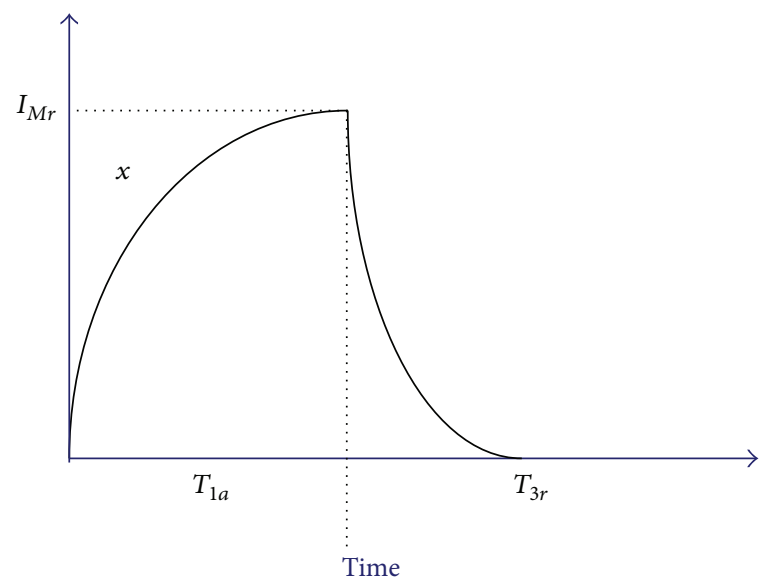

FIGURE 2: Inventory status of recoverable items.

Hence, the total inventory of recoverable items in a production uptime is

$$
T T I_{r 1}=\frac{x t_{1 a}^{2}}{2}
$$

and the maximum recoverable inventory is

$$
I_{M r}=I_{r 1}\left(T_{1 a}\right)=x T_{1 a} .
$$

The inventory level of recoverable item in the rework uptime is modeled as

$$
\frac{d I_{r 3}\left(t_{r 3}\right)}{d t_{r 3}}=-P_{1}, \quad 0 \leq t_{r 3} \leq T_{3 r} .
$$

Using $I_{r 3}\left(T_{3 r}\right)=0$, the inventory level of recoverable item in rework uptime is

$$
I_{r 3}\left(t_{r 3}\right)=P_{1}\left(T_{3 r}-t_{r 3}\right), \quad 0 \leq t_{r 3} \leq T_{3 r} .
$$

Hence, the total inventory of recoverable item in the rework uptime is

$$
\operatorname{TTI}_{r 3}=\frac{P_{1} T_{3 r}^{2}}{2} .
$$

The number of recoverable inventories is

$$
I_{M r}=I_{r 3}(0)=P_{1} T_{3 r} .
$$

Hence,

$$
T_{3 r}=\frac{I_{M r}}{P_{1}} .
$$

Substituting $I_{M r}$ from (15), we get

$$
T_{3 r}=\frac{x T_{1 a}}{P_{1}} .
$$

Hence, the total recoverable inventory is

$$
I_{w}=T T I_{r 1}+T T I_{r 3}=\frac{x T_{1 a}^{2}}{2}\left(1+\frac{x}{P_{1}}\right) .
$$


The inventory level at the beginning of the production downtime is equal to the inventory level at the end of the production uptime; that is,

$$
I_{1 a}\left(T_{1 a}\right)=I_{2 a}(0) .
$$

Therefore,

$$
T_{2 a} \approx \frac{1}{a}\left[(P-a-x) T_{1 a}-\frac{a b}{2} T_{1 a}^{2}\right] .
$$

When $t_{3 r}=T_{3 r}$ and $t_{4 r}=0$, the inventory level for serviceable item in rework process satisfies

$$
\left(P_{1}-a-x_{1}\right) T_{3 r}-\frac{a b}{2} T_{3 r}^{2}=a\left[T_{4 r}-\frac{b}{2} T_{4 r}^{2}\right] .
$$

Neglecting $T_{4 r}^{2}$ (because $0<T_{4 r}<1$ ), we get

$$
T_{4 r} \approx \frac{1}{a}\left(P_{1}-a-x_{1}\right) \frac{x}{P_{1}} T_{1 a} .
$$

The total production inventory cost is the sum of the production set up cost, inventory cost of serviceable item, inventory cost of recoverable item, and scrap cost:

$$
\begin{aligned}
T C= & A+h\left[T I_{1 a}+T I_{3 r}+T I_{2 a}+T I_{4 r}+T I_{3 a}\right] \\
& +h_{1} I_{w}+S_{C} x_{1} T_{3 r}
\end{aligned}
$$

and the total cycle time is

$$
T=T_{1 a}+T_{3 r}+T_{2 a}+T_{4 r} .
$$

Hence, the total cost per unit time without lost sales is given by

$$
\mathrm{TCT}_{\mathrm{NL}}=\frac{T C}{T} .
$$

The optimal production uptime for the EPQ system without lost sales can be obtained by setting

$$
\frac{d T C T_{\mathrm{NL}}\left(T_{1 a}\right)}{d T_{1 a}}=0 .
$$

When unavailability time of a machine is longer than the production downtime duration, lost sales will occur. So the total inventory cost is

$$
\begin{aligned}
E(T C)= & A+h\left[T I_{1 a}+T I_{3 r}+T I_{2 a}+T I_{4 r}+T I_{3 a}\right] \\
& +h_{1} I_{w}+S_{C} x_{1} T_{3 r}+S_{L} \\
& \times \int_{t=T_{2 a}+T_{4 r}}^{\infty} R(t)\left(t-\left(T_{2 a}+T_{4 r}\right)\right) f(t) d t
\end{aligned}
$$

and the total cycle time for lost sales is

$$
\begin{aligned}
E(T)= & T_{1 a}+T_{3 r}+T_{2 a}+T_{4 r} \\
& +\int_{t=T_{2 a}+T_{4 r}}^{\infty}\left(t-\left(T_{2 a}+T_{4 r}\right)\right) f(t) d t .
\end{aligned}
$$

Hence, the total cost per unit time for lost sales is

$$
E(T C T)=\frac{E(T C)}{E(T)} .
$$

We discuss lost sales scenario for two distributions, namely uniform distribution and exponential distribution.
2.1. Uniform Distribution. Define the probability distribution function $f(t)$, when the preventive maintenance time $t$ is distributed uniformly as follows:

$$
f(t)= \begin{cases}\frac{1}{\tau}, & 0 \leq t \leq \tau \\ 0, & \text { otherwise }\end{cases}
$$

Substituting $f(t)$ in (33) gives the total cost per unit time for uniform distribution as

$$
\begin{aligned}
& \operatorname{TCT}_{U} \\
& =\left(A+h\left[T I_{1 a}+T I_{3 r}+T I_{2 a}+T I_{4 r}+T I_{3 a}\right]+h_{1} I_{w}\right. \\
& \left.\quad+S_{C} x_{1} T_{3 r}+S_{L} \int_{0}^{\tau}\left(\frac{a(1+b t)}{\tau}\right)\left(t-\left(T_{2 a}+T_{4 r}\right)\right) d t\right) \\
& \times\left(T_{1 a}+T_{3 r}+T_{2 a}+T_{4 r}+\left(\frac{1}{\tau}\right)\right. \\
& \left.\quad \times \int_{t=T_{2 a}+T_{4 r}}^{\tau}\left(t-\left(T_{2 a}+T_{4 r}\right)\right) d t\right)^{-1}
\end{aligned}
$$

substituting all the time variables in (35) in terms of $T_{1 a}$, the objective function; $T C T_{u}$ is a function of $T_{1 a}$ only. The optimum value of $T_{1 a}$ can be computed by setting

$$
\frac{d T C T_{U}\left(T_{1 a}\right)}{d T_{1 a}}=0 .
$$

To derive the best solution from nonlost sales and lost sales scenarios, we propose the following steps [17].

Step 1. Calculate (30), (24), and (26) and set $T_{\mathrm{sb}}=T_{2 a}+T_{4 r}$.

Step 2. If $T_{\mathrm{sb}}<\tau$, then the obtained solution is not feasible, and go to Step 3; otherwise the solution is obtained.

Step 3. Set $T_{\mathrm{sb}}=\tau$. Find $T_{\text {laub }}$ using (26) and (24). Calculate $T C T_{\mathrm{NL}}\left(T_{\text {laub }}\right)$ using $(29)$.

Step 4. Calculate (36), (24), and (26) and set $T_{\mathrm{sb}}=T_{2 a}+T_{4 r}$.

Step 5. If $T_{\mathrm{sb}} \geq \tau$, then $T_{1 a}^{*}=T_{1 \mathrm{aub}}$ and the corresponding total cost is $T C T_{\mathrm{NL}}\left(T_{1 \mathrm{aub}}\right)$; otherwise, calculate $\operatorname{TC} T_{U}\left(T_{1 a}\right)$.

Step 6. If $T C T_{\mathrm{NL}}\left(T_{1 \mathrm{aub}}\right) \leq T C T_{U}\left(T_{1 a}\right)$, then $T_{1 a}^{*}=T_{1 \mathrm{aub}}$ : otherwise $T_{1 a}^{*}=T_{1 a}$.

2.2. Exponential Distribution. Define the probability distribution function $f(t)$, when the preventive maintenance time $t$ is distributed exponential with mean $1 / \lambda$ as

$$
f(t)=\lambda e^{-\lambda t}, \quad \lambda>0 .
$$




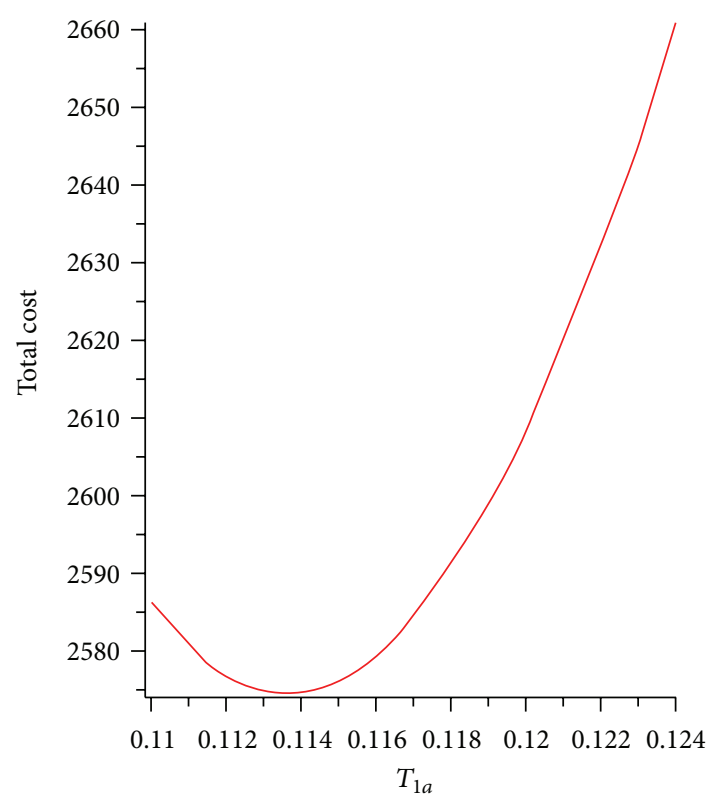

FIgURe 3: Convexity of total cost.

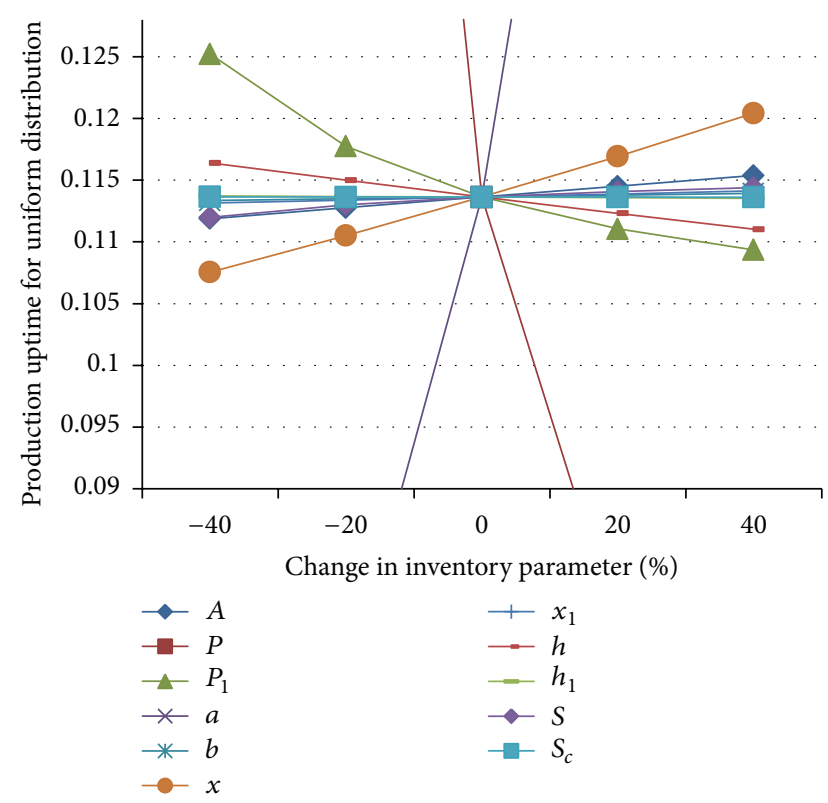

FIGURE 4: Sensitivity analysis of production uptime for uniform distribution.

Here, the total cost per unit time for the lost sale $S_{L}$ is

$$
\begin{aligned}
\operatorname{TCT}_{E}=( & A+h\left[T I_{1 a}+T I_{3 r}+T I_{2 a}+T I_{4 r}+T I_{3 a}\right] \\
& +h_{1} I_{w}+S_{C} x_{1} T_{3 r} \\
& \left.+S_{L} \int_{t=T_{2 a}+T_{4 r}}^{\infty} R(t)\left(t-\left(T_{2 a}+T_{4 r}\right)\right) \lambda e^{-\lambda t} d t\right) \\
& \times\left(T_{1 a}+T_{3 r}+T_{2 a}+T_{4 r}+\left(\frac{1}{\lambda}\right) e^{-\lambda\left(T_{2 a}+T_{4 r}\right)}\right)^{-1}
\end{aligned}
$$

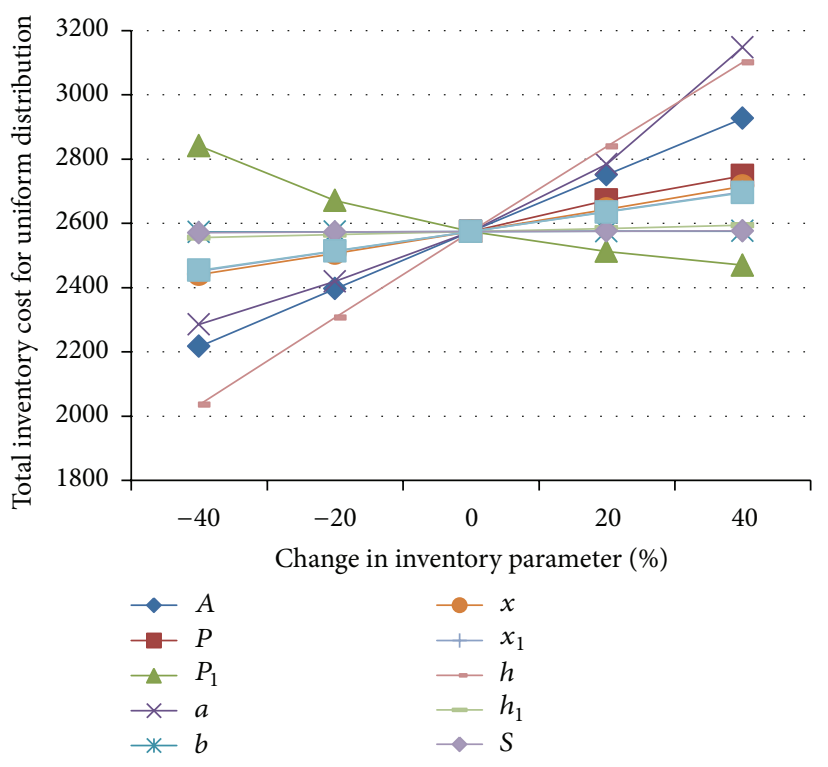

FIGURE 5: Sensitivity analysis of total cost for uniform distribution.

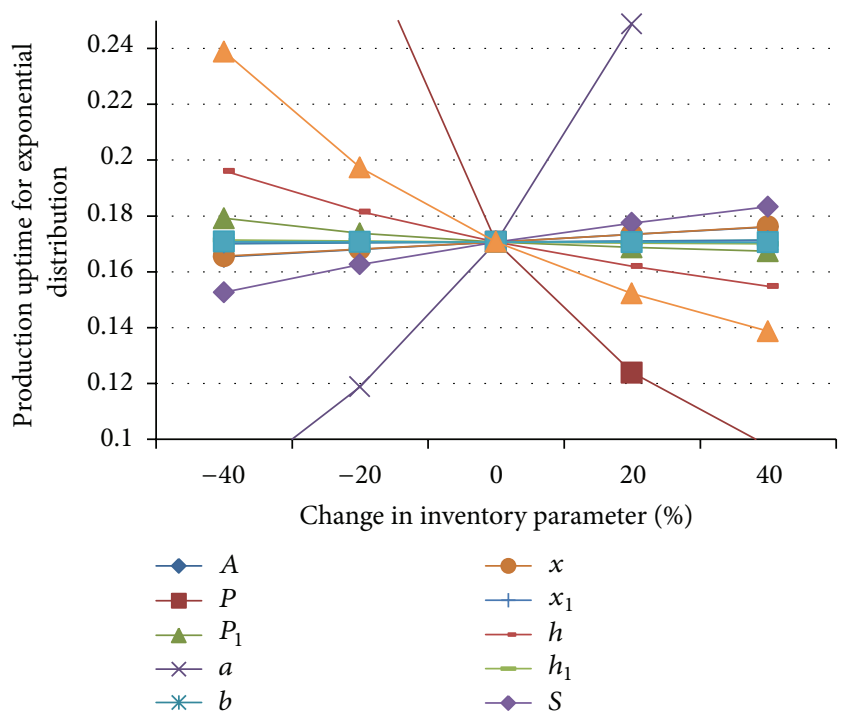

FIGURE 6: Sensitivity analysis of production uptime for exponential distribution.

Arguing as in (Section 2.1), we can obtain optimum total cost. The high nonlinearity of the cost functions (29), (35), and (38) does not guarantee that the optimal solution is global. However, using parametric values, convexity of the objective function is established.

\section{Numerical Examples and Sensitivity Analysis}

Consider, following parametric values to study the working of the proposed problem. Let $A=\$ 200$ per production cycle, $P=10,000$ units per unit time, $a=5000$ units per unit time, $b=10 \%, x=500$ units per unit time; $x_{1}=400$ units per unit time, $h=\$ 5$ per unit per unit time. $h_{1}=$ 


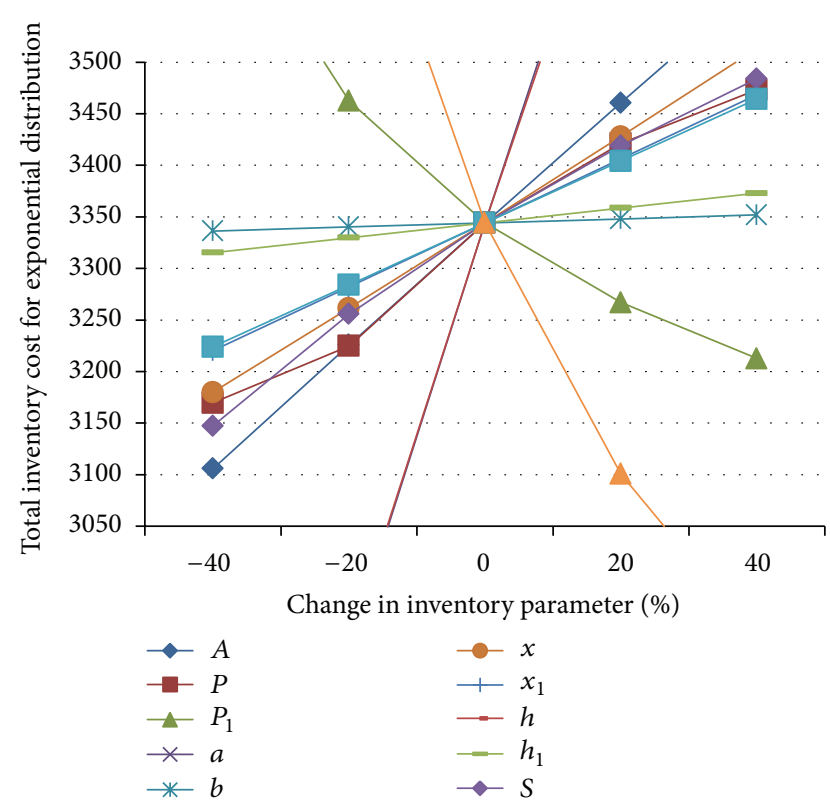

FIGURE 7: Sensitivity analysis of total cost for exponential distribution.

$\$ 3$ per unit per unit time, $S_{L}=\$ 10$ per unit, $S_{C}=\$ 12$ per unit, and the preventive maintenance time is uniformly distributed over the interval [0,0.1] [17]. Using the solution procedure outlined, the optimal production uptime is $T_{1 a}=$ 41.5 days and the corresponding minimum total cost per unit time is $T C T_{U}=\$ 2575$. This establishes that some lost sales reduce the total cost per unit time. The convexity of $T C T_{U}$ is established in Figure 3.

The sensitivity analysis is carried out by changing each of the parameters by $-40 \%,-20 \%,+20 \%$, and $+40 \%$. The optimal production uptime $T_{1 a}$ and the optimal total cost per unit time for inventory parameters under consideration are shown in Table 1.

Figures 4 and 6 depict sensitivity analysis of production uptime, $T_{1 a}$, with respect to all the inventory parameters considered in the modeling when preventive maintenance time follows uniform distribution/exponential distribution. It is observed that production uptime is slightly sensitive to changes in $P$ and $a$ and moderately sensitive to changes in $b$ and $\tau$, with little impact due to changes in the other inventory parameters. $T_{1 a}$ has negative impact with the increase in the production rate, $P$, and positive impact when scale demand, $a$, and rate of demand, $b$, increase.

The optimal total cost per unit time is slightly sensitive to changes in $a, P, x$, and $L$ and moderately sensitive to changes in $A, b, \tau, S_{C}, x_{1}$, and $S_{L}$. No change is observed in the optimal total cost per unit time for the remaining inventory parameters. The optimal total cost per unit time is inversely related to $P$ and $P_{1}$ and directly related to other inventory parameters (see Figures 5 and 7).

\section{Conclusions}

In this research, rework of imperfect quality and random preventive maintenance time are incorporated in economic production quantity model when demand increases with time. The random preventive maintenance time is distributed uniformly and exponentially. The models are validated by the example. The sensitivity analysis suggests that the optimal total cost per unit time is sensitive to changes in the production rate, the demand rate, and the product defect rate in both the uniform and the exponential distributed preventive maintenance time. To combat increasing demand, the management should adopt the latest machinery which decreases defective production rate, reducing rework, and as a consequence, the machine's production uptime can be utilized to its utmost. Further research can be carried out to study the effect of deterioration of units.

\section{Notations}

$I_{1 a}$ : Serviceable inventory level in a production uptime

$I_{2 a}$ : Serviceable inventory level in a production downtime

$I_{3 a}$ : Serviceable inventory level in a rework uptime

$I_{3 r}$ : Serviceable inventory level from rework uptime

$I_{4 r}$ : Serviceable inventory level from rework process in rework downtime

$I_{r 1}$ : Recoverable inventory level in a production uptime

$I_{r 3}$ : Recoverable inventory level in a rework uptime

$T I_{1 a}$ : Total serviceable inventory in a production uptime

$T I_{2 a}$ : Total serviceable inventory in a production downtime

$T I_{3 a}$ : Total serviceable inventory in a rework uptime

$T I_{3 r}$ : Total serviceable inventory from a rework uptime

$T I_{4 r}$ : Total serviceable inventory from rework process in a rework downtime

$T T I_{r 1}$ : Total recoverable inventory level in a production uptime

$T T I_{r 3}$ : Total recoverable inventory level in a rework uptime

$T_{1 a}: \quad$ Production uptime

$T_{2 a}$ : Production downtime

$T_{3 r}$ : Rework uptime

$T_{4 r}$ : Rework downtime

$T_{\mathrm{sb}}$ : Total production downtime

$T_{\text {laub}}$ : Production uptime when the total production downtime is equal to the upper bound of uniform distribution parameter

$I_{m}$ : Inventory level of serviceable items at the end of production uptime

$I_{M r}$ : Maximum inventory level of recoverable items in a production uptime

$I_{w}: \quad$ Total recoverable inventory 


$\begin{array}{ll}P: & \text { Production rate } \\ P_{1}: & \text { Rework process rate } \\ R=R(t): & \text { Demand rate; } a(1+b t), a>0,0<b<1 \\ x: & \text { Product defect rate } \\ x_{1}: & \text { Product scrap rate } \\ A: & \text { Production setup cost } \\ h: & \text { Serviceable items holding cost } \\ h_{1}: & \text { Recoverable items holding cost } \\ S_{C}: & \text { Scrap cost } \\ S_{L}: & \text { Lost sales cost } \\ T C: & \text { Total inventory cost } \\ T: & \text { Cycle time } \\ T C T: & \text { Total inventory cost per unit time for } \\ T C T_{\mathrm{NL}}: & \text { lost sales model } \\ T C T_{U}: & \text { Total inventory cost per unit time for } \\ & \text { Total inventory cost per unit time } \\ & \text { for lost sales model with uniform dis- } \\ \text { tribution preventive maintenance time }\end{array}$

\section{References}

[1] D. A. Schrady, "A deterministic inventory model for repairable items," Naval Research Logistics, vol. 14, no. 3, pp. 391-398, 1967.

[2] M. Khouja, "The economic lot and delivery scheduling problem: common cycle, rework, and variable production rate," IIE Transactions, vol. 32, no. 8, pp. 715-725, 2000.

[3] S.-G. Koh, H. Hwang, K.-I. Sohn, and C.-S. Ko, "An optimal ordering and recovery policy for reusable items," Computers and Industrial Engineering, vol. 43, no. 1-2, pp. 59-73, 2002.

[4] I. Dobos and K. Richter, "An extended production/recycling model with stationary demand and return rates," International Journal of Production Economics, vol. 90, no. 3, pp. 311-323, 2004.

[5] S. W. Chiu, D.-C. Gong, and H.-M. Wee, "Effects of random defective rate and imperfect rework process on economic production quantity model," Japan Journal of Industrial and Applied Mathematics, vol. 21, no. 3, pp. 375-389, 2004.

[6] A. M. M. Jamal, B. R. Sarker, and S. Mondal, "Optimal manufacturing batch size with rework process at a single-stage production system," Computers and Industrial Engineering, vol. 47, no. 1, pp. 77-89, 2004.

[7] L. E. Cárdenas-Barrón, "On optimal batch sizing in a multistage production system with rework consideration," European Journal of Operational Research, vol. 196, no. 3, pp. 1238-1244, 2009.

[8] G. A. Widyadana and H. M. Wee, "Revisiting lot sizing for an inventory system with product recovery," Computers and Mathematics with Applications, vol. 59, no. 8, pp. 2933-2939, 2010.

[9] S. W. Chiu, "Optimal replenishment policy for imperfect quality EMQ model with rework and backlogging," Applied Stochastic Models in Business and Industry, vol. 23, no. 2, pp. 165-178, 2007.

[10] S. W. Chiu, C.-K. Ting, and Y.-S. P. Chiu, "Optimal production lot sizing with rework, scrap rate, and service level constraint," Mathematical and Computer Modelling, vol. 46, no. 3-4, pp. 535549, 2007.
[11] S. H. Yoo, D. Kim, and M.-S. Park, "Economic production quantity model with imperfect-quality items, two-way imperfect inspection and sales return," International Journal of Production Economics, vol. 121, no. 1, pp. 255-265, 2009.

[12] R. D. Meller and D. S. Kim, "The impact of preventive maintenance on system cost and buffer size," European Journal of Operational Research, vol. 95, no. 3, pp. 577-591, 1996.

[13] S.-H. Sheu and J.-A. Chen, "Optimal lot-sizing problem with imperfect maintenance and imperfect production," International Journal of Systems Science, vol. 35, no. 1, pp. 69-77, 2004.

[14] J.-C. Tsou and W.-J. Chen, "The impact of preventive activities on the economics of production systems: modeling and application," Applied Mathematical Modelling, vol. 32, no. 6, pp. 10561065, 2008.

[15] N. E. Abboud, M. Y. Jaber, and N. A. Noueihed, "Economic lot sizing with the consideration of random machine unavailability time," Computers and Operations Research, vol. 27, no. 4, pp. 335-351, 2000.

[16] C.-J. Chung, G. A. Widyadana, and H. M. Wee, "Economic production quantity model for deteriorating inventory with random machine unavailability and shortage," International Journal of Production Research, vol. 49, no. 3, pp. 883-902, 2011.

[17] H. M. Wee and G. A. Widyadana, "Economic production quantity models of deteriorating items with rework and stochastic preventive maintenance time," International Journal of Production Research, vol. 50, no. 11, pp. 2940-2952, 2012. 


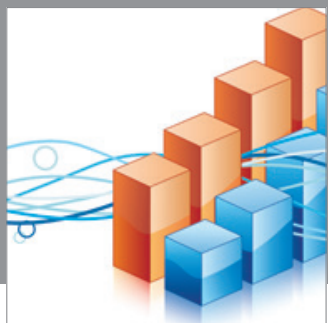

Advances in

Operations Research

mansans

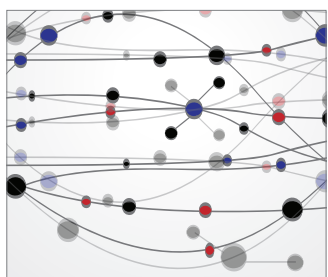

The Scientific World Journal
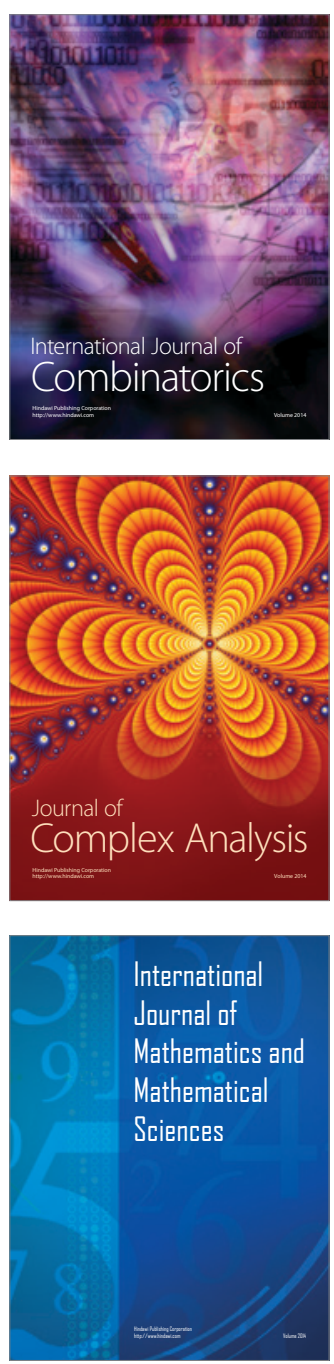
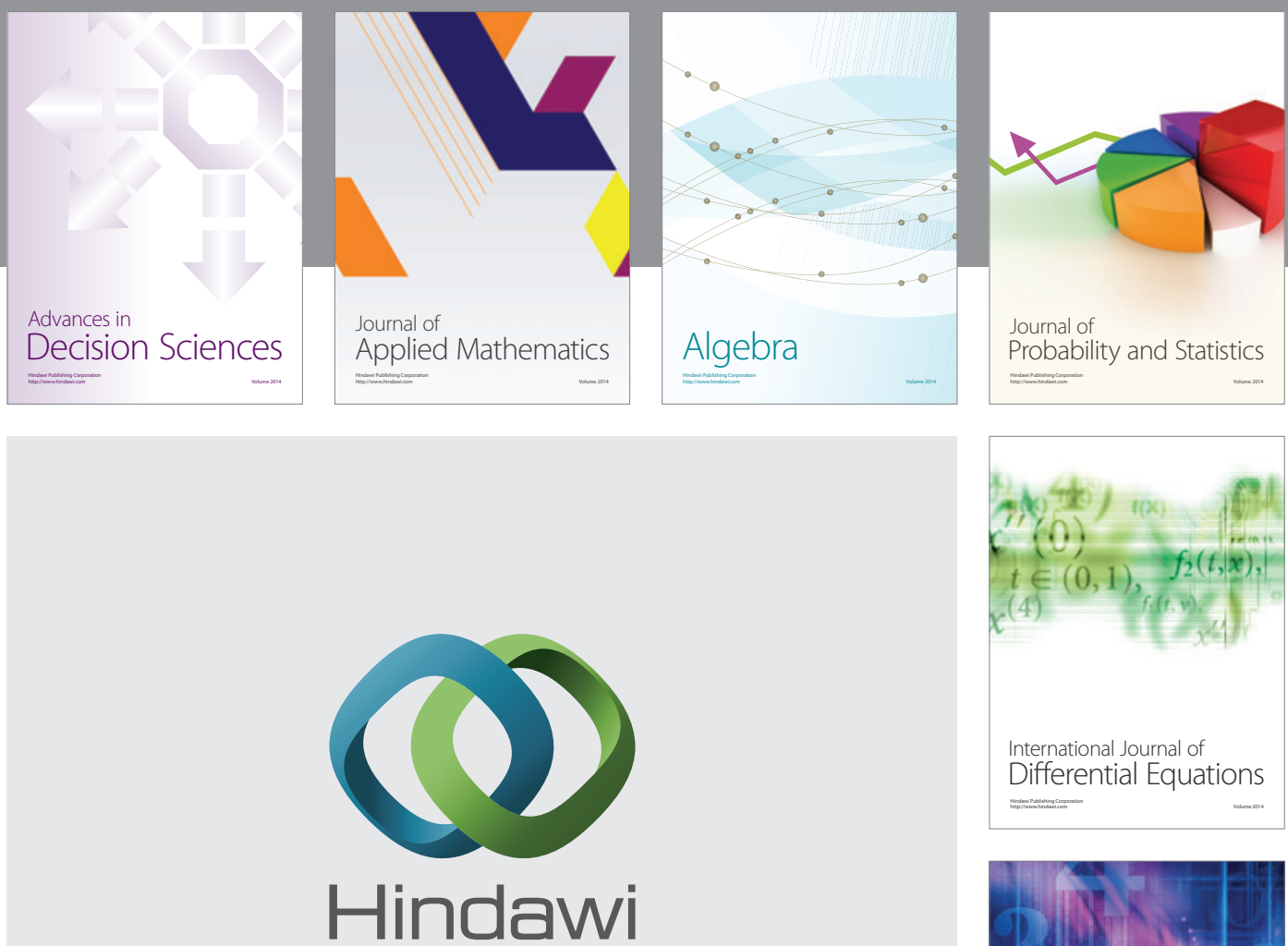

Submit your manuscripts at http://www.hindawi.com
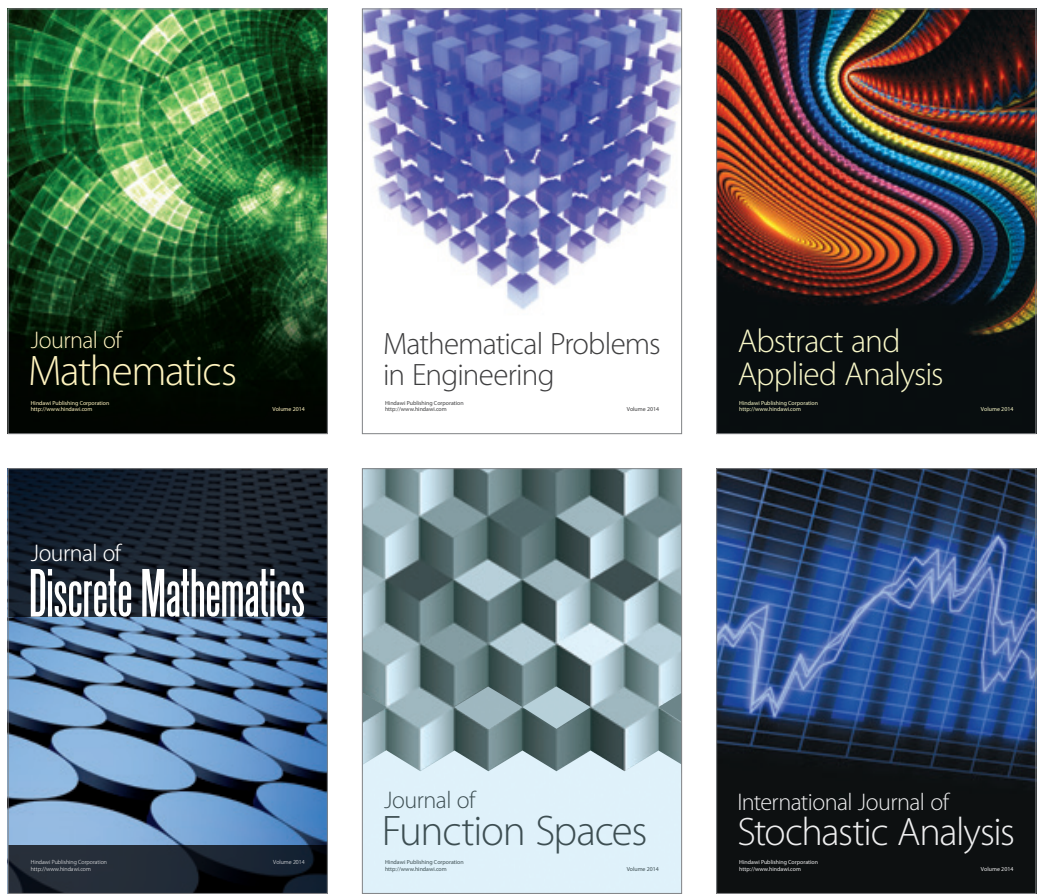

Journal of

Function Spaces

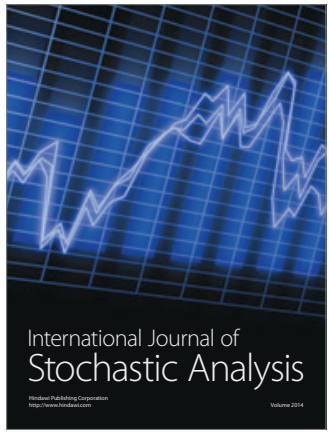

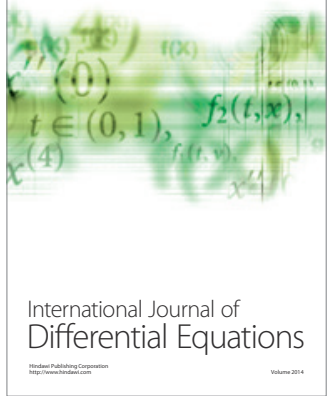
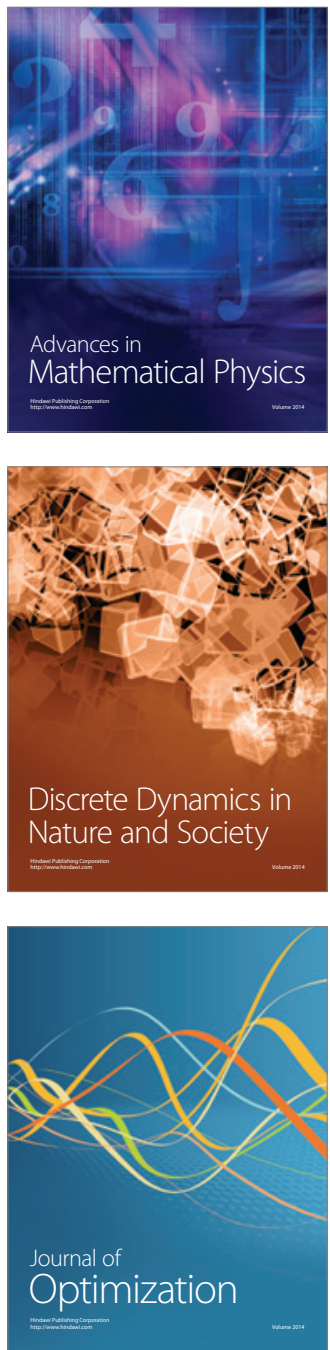